\title{
The Gene-Lifestyle Interaction on Leptin Sensitivity and Lipid Metabolism in Adults: A Population Based Study
}

\author{
Harry Freitag Luglio ${ }^{1, *}$, Dian Caturini Sulistyoningrum ${ }^{1}$, Emy Huriyati ${ }^{1}$, Yi Yi Lee ${ }^{2}$ \\ and Wan Abdul Manan Wan Muda ${ }^{3}$ \\ 1 Department of Nutrition and Health, Faculty of Medicine, Universitas Gadjah Mada, Yogyakarta 55281, \\ Indonesia; dian.csulis@gmail.com (D.C.S.); emy_huriyati@ugm.ac.id (E.H.) \\ 2 School of Health Sciences, Universiti Sains Malaysia, Gelugor 11800, Malaysia; leeyy.yiyi@gmail.com \\ 3 Center for Southeast Asian Studies, Kyoto University, Kyoto 606-8501, Japan; wanmanan@gmail.com \\ * Correspondence: harryfreitag@ugm.ac.id; Tel./Fax: +62-274-547-775
}

Received: 31 May 2017; Accepted: 30 June 2017; Published: 7 July 2017

\begin{abstract}
Background: Obesity has been associated with leptin resistance and this might be caused by genetic factors. The aim of this study was to investigate the gene-lifestyle interaction between -866G/A UCP2 (uncoupling protein 2) gene polymorphism, dietary intake and leptin in a population based study. Methods: This is a cross sectional study conducted in adults living at urban area of Yogyakarta, Indonesia. Data of adiposity, lifestyle, triglyceride, high density lipoprotein (HDL) cholesterol, leptin and UCP2 gene polymorphism were obtained in 380 men and female adults. Results: UCP2 gene polymorphism was not significantly associated with adiposity, leptin, triglyceride, HDL cholesterol, dietary intake and physical activity (all $p>0.05$ ). Leptin was lower in overweight subjects with AA + GA genotypes than those with GG genotype counterparts $(p=0.029)$. In subjects with AA + GA genotypes there was a negative correlation between leptin concentration $(r=-0.324$; $p<0.0001)$ and total energy intake and this correlation was not seen in GG genotype $(r=-0.111$; $p=0.188$ ). Conclusions: In summary, we showed how genetic variation in $-866 \mathrm{G} / \mathrm{A} \mathrm{UCP} 2$ affected individual response to leptin production. AA + GA genotype had a better leptin sensitivity shown by its response in dietary intake and body mass index (BMI) and this explained the protective effect of $\mathrm{A}$ allele to obesity.
\end{abstract}

Keywords: UCP2; leptin; dietary intake; adiposity; obesity

\section{Introduction}

Obesity is an emerging health problem in developing countries [1] because its association with a greater risk to non-communicable diseases such as type 2 diabetes mellitus and cardiovascular diseases [2]. In the last few decades, there has been increasing number of studies that evaluate the etiology of obesity. Majority of biological investigation was focused on the role of pathways in energy metabolism and appetite regulation. Leptin is one of the protein that involved in normal body weight maintenance by regulation of energy homeostasis and food intake [3].

Leptin is a protein that produced mainly by adipose tissue and its production is increased as adipose tissue enlarge [4]. This mechanism is suggested as a homeostasis effort of the body to prevent further weight gain. Nevertheless, leptin appeared to be higher in obese individuals than in normal and this phenomena is suggested as leptin resistance. Leptin resistance is introduced to express the reduced ability to decrease appetite and dietary intake as well as to prevent further weight gain [5]. Until now, it is not clear which factors are responsible for leptin resistance in human. 
There were several studies conducted to evaluate which factors that have been associated with leptin in human. Genetic variation on LEP (leptin) and LEPR (leptin receptor) were previously reported be associated with leptin concentration [6-8]. However, to our knowledge, there was no study investigating the role of genetic variation in leptin sensitivity in human. Therefore, we aimed to evaluate whether genetic variation in protein that involved in the leptin signalling pathway that is responsible for leptin resistance.

In this study, we analyzed the association between genetic variation in UCP2 gene and leptin sensitivity in Indonesian population. UCP2 is a subtype of uncoupling proteins which are presented in mitochondria and involved in energy regulation $[9,10]$. In a population based study, it was shown that UCP2 gene polymorphism was associated with obesity [11,12]. However, it is unclear how UCP2 gene polymorphism was associated with obesity in human. It was previously reported that UCP2 polymorphism was associated with leptin production [13]. Studies in animal trial [14] and human cells [15] showed that leptin was able to induce UCP2 expression.

Because leptin and UCP2 were involved in energy metabolism, we speculated that there might be an interplay between UCP2 gene polymorphism and leptin sensitivity. Therefore, the aim of this study was to investigate the gene-lifestyle interaction between UCP2, dietary intake and leptin sensitivity in a population based study. Because leptin has an ability to affect appetite and dietary intake, leptin sensitivity was determined by analyzing the correlation between leptin and dietary intake. The correlation between leptin and adiposity also being analyzed separately based on their genotypes to show the differential response towards leptin production. To our knowledge, this is the first study to evaluate the role of UCP2 on leptin sensitivity instead of only leptin production.

\section{Methods}

\subsection{Design and Study Population}

This was a cross sectional study conducted in the province of Yogyakarta, Indonesia. The subjects were adult men and women with age between 21-56 years old living in the urban area of Yogyakarta city. A total of 380 individuals was selected using a stratified random sampling. Five sub-districts of the city were chosen which represented the area based on population density and subjects were selected randomly. The inclusion criteria were the permanent residents in the area and agree to become subjects of this study by signing the informed consent. The exclusion criteria are those who diagnosed with degenerative diseases such as diabetes, cardiovascular disease, or cancer, pregnant at the moment when the study was done, have a strict diet and have a problem with walking or conducting physical activity in the last 6 months. Ethical clearance was obtained from Ethical Clearance from Medical and Health Research Ethics Committee (MHREC) Faculty of Medicine, Universitas Gadjah Mada, Indonesia (KE/FK/791/EC/2015). This study followed the ethical guidelines of the 1975 Declaration of Helsinki.

\subsection{Anthropometric Measurements}

Nutritional status was defined by body mass index, which calculated by dividing body weight with the square of height. Body weight was measured using a digital body mass scale $(0.01 \mathrm{~kg}$ precision, Omron, Osaka, Japan) while the height was measured using microtoise $(0.1 \mathrm{~cm}$ precision, GEA medical, Jakarta, Indonesia). Definition of overweight was BMI (body mass index) higher than $25 \mathrm{~kg} / \mathrm{m}^{2}$ while obesity was defined when BMI was higher than $30 \mathrm{~kg} / \mathrm{m}^{2}$. All anthropometric measurements were done by trained enumerators using calibrated instruments. Waist and hip circumference were measured using a non elastic tape with precision of $0.1 \mathrm{~cm}$ (OneMed, Surabaya, Indonesia). Percent body fat was measured using bioelectrical impedance analysis (Omron, Osaka, Japan). 


\subsection{Lifestyle Analysis}

Data on lifestyle factors were measured based on dietary intake and physical activity. Data on dietary intake was collected using a semi quantitative food frequency questionnaire (SQ-FFQ) and the analysis was conducted using Nutrisurvey software (EBISpro, Stuttgart, Germany). Data of habitual consumption of food items were collected using SQ-FFQ translated into daily intake. Energy intake was calculated based on total energy (in kcal) that was provided by those food items consumed by subjects. This method was also used to calculate other nutrient consumption, such as protein, fat, and carbohydrate. Database of energy and nutrients content of food items was provided by Nutrisurvey. Data on physical activity was collected using an international physical activity questionnaire (IPAQ). This questionnaire contains information on the intensity and duration for several activities including work/job, transportation, house related work and maintenance, recreation, exercise and leisure-time physical activity. Each activity has a unique MET (metabolic equivalent of task) score, which represent the amount of energy used for a certain type of activity. In order to obtain a great picture of individual physical activity for the whole week, all the activities that has been reported in IPAQ form then calculated into MET-minutes/weeks. The SQ-FFQ and IPAQ were developed and validated before.

\subsection{Blood Collection and Biochemistry Analysis}

A total of $10 \mathrm{~mL}$ subjects blood specimens was collected in Ethylenediaminetetraacetic acid (EDTA)-containing tubes. After collection, blood plasma and buffy coat were separated using a centrifuge. Plasma HDL cholesterol and triglyceride concentration were measured using cholesterol oxidase phenol 4-aminoantipyrine peroxidase (CHOD-PAP) and glycerol phosphate oxidase (GPO) method, respectively (Diasys, Holzheim, Germany). Leptin was measured using enzyme linked immunosorbent assay (DRG, Springfield Township, NJ, USA).

\subsection{Genetic Analysis}

The DNA sample was isolated from buffy coat using a commercial DNA extraction kit (Favorgen, Pingtung City, Taiwan). UCP2 -866G/A genotyping was done using polymerase chain reaction-restriction fragment length polymorphism (PCR-RFLP) with forward primer: 5'-CACGCTGCTTCTGCCAGGAC-3' and reverse primer: 5'-AGGCTCAGGAGATGGACCG-3'. PCR conditions are: $8 \mathrm{~min}$ of denaturation in $95^{\circ} \mathrm{C}$ followed by 35 cycles of $95^{\circ} \mathrm{C}$ for 1 min (denaturation), $55^{\circ} \mathrm{C}$ for $1 \mathrm{~min}$ (annealing), $68^{\circ} \mathrm{C}$ for $1 \mathrm{~min}$ (extension) and $72{ }^{\circ} \mathrm{C}$ for $7 \mathrm{~min}$ (final extension). The PCR product then digested using BST UI enzyme digestion. Restriction fragments were resolved on a $3 \%$ agarose gel.

\subsection{Statistical Analysis}

Statistical analysis was conducted in using GraphPad Prism version 5.00 for Windows (GraphPad Software, La Jolla, CA, USA). Subjects were separated into 2 groups: AA + GA and GG. The difference in anthropometric measures, lipid profile, leptin, dietary intake and physical activity between AA + GA and GG genotypes were analyzed using Mann Withney test. Leptin concentration was compared between genotypes and nutritional status using Mann Withney test. A Spearman analysis was done to evaluate the correlation between leptin and dietary intake in each genotype group. A partial correlation analysis was performed to test the correlation between leptin and dietary intake in each genotypes controlled by age, gender and body weight. All statistical analysis was conducted in 2 tail analysis and significance was threshold when $p<0.05$.

\section{Results}

This is an observational study conducted in the urban area of Yogyakarta, Indonesia. Subjects were $41.7 \pm 11.1$ years old. To rule out the influence of confounding factors of leptin production such as gender, age and adiposity, the authors calculated the distribution of those characteristics 
in this study. Men $(n=174)$ and women $(n=206)$ were distributed equally $(45.8 \%$ and $54.2 \%$, respectively). The distribution of age group were $16.6 \%$ for $21-29.9$ years old group; $23.2 \%$ for $30-39.9$ years old group; $30 \%$ for $40-49.9$ years old group and $30 \%$ for $50-56$ years old group. In study 26 subjects $(6.8 \%)$ were underweight $\left(\mathrm{BMI}<18.5 \mathrm{~kg} / \mathrm{m}^{2}\right), 176$ subjects $(46.3 \%)$ were normal weight (BMI $\left.18.5-25 \mathrm{~kg} / \mathrm{m}^{2}\right), 114$ subjects $(30 \%)$ were overweight (BMI $25-30 \mathrm{~kg} / \mathrm{m}^{2}$ ) and 64 subjects $(16.8 \%)$ were obese (BMI $\left.>30 \mathrm{~kg} / \mathrm{m}^{2}\right)$. The variation of UCP2 gene polymorphism in this study was under Hardy Weinberg Equation $\left(X^{2}=0.206, p=0.649\right)$. Gender in all UCP2 genotypes were equally distributed: AA male $=26(48.1 \%)$, female $=32(51.9 \%) ;$ GA male $=89(48.4 \%)$, female $=95(51.6 \%)$, GG male $=59$ $(41.5 \%)$, female $=83(58.5 \%)$. Table 1 shows the comparison of anthropometric, lipid profile, leptin, dietary intake and physical activity between UCP2 genotypes. In this study, we showed that UCP2 gene polymorphism in Indonesian adults was not associated with adiposity, lipid profile and leptin production. There were no differences in energy intake and physical activity between those genotypes.

Plasma leptin concentration between nutritional statuses were compared (Figure 1). There were no differences in leptin concentration between AA + GA and GG group in normal weight and obese individuals. In subjects with overweight, we showed that leptin concentration in the GG group was significantly higher than those in AA + GA group $(p=0.029)$.

The correlation between leptin on adiposity, lipid profile and lifestyle factors were analyzed separately depend on UCP2 gene variation. Table 2 shows the correlation between leptin, adiposity and lipid profile. Leptin was correlated with adiposity in both single nucleotide polymorphisms (SNPs). Interestingly, leptin was associated with increased HDL level only in individuals with AA + GA genotypes $(p=0.022)$ and this correlation was not seen in GG genotypes $(p=0.822)$. Table 3 shows the correlation between leptin and lifestyle factors. The correlation between leptin and dietary intake was not seen in GG group. By contrast, leptin was negatively correlated with all dietary intake aspects of individuals in AA + GA group and this correlation is still significant after controlled for age, gender and body weight. In both groups, leptin was not correlated with physical activity.

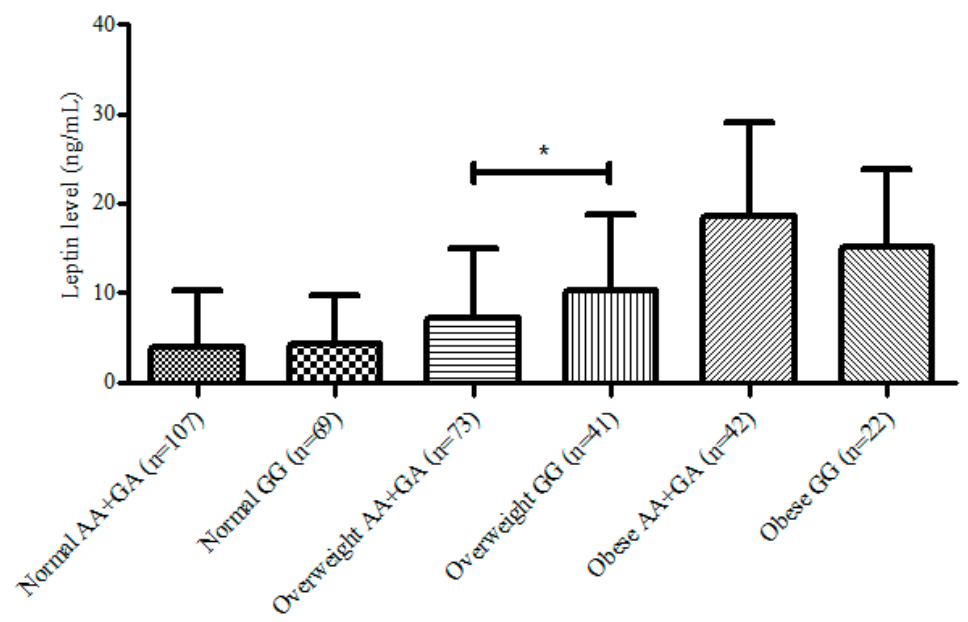

Figure 1. Difference in leptin production across genotypes and nutritional statuses. ${ }^{*}$ Mann Whitney test $p<0.05$. 
Table 1. Anthropometric, biochemical and lifestyle variation between genotypes.

\begin{tabular}{|c|c|c|c|c|c|}
\hline Measurements & Total $(n=380)$ & AA $(n=54)$ & GA $(n=184)$ & GG $(n=142)$ & $p_{\mathrm{AA}}+\mathrm{GA}$ vs. GG $*$ \\
\hline Age (years) & $41.7 \pm 11.1(40.0)$ & $40.8 \pm 10.9(44.0)$ & $42.4 \pm 9.8(42.0)$ & $41.2 \pm 12.8(43.0)$ & 0.523 \\
\hline \multicolumn{6}{|l|}{ Anthropometric measurements } \\
\hline Body weight $(\mathrm{kg})$ & $62.3 \pm 13.8(61.4)$ & $62.1 \pm 14.4(61.5)$ & $62.8 \pm 13.8(62.2)$ & $61.7 \pm 13.7(61.2)$ & 0.518 \\
\hline Height $(\mathrm{cm})$ & $157.3 \pm 9.4(156.9)$ & $157.2 \pm 8.7(156.2)$ & $157.4 \pm 9.9(157.0)$ & $157.1 \pm 9.2(156.8)$ & 0.748 \\
\hline BMI $\left(\mathrm{kg} / \mathrm{m}^{2}\right)$ & $25.2 \pm 5.3(24.6)$ & $25.2 \pm 5.5(25.5)$ & $25.3 \pm 5.4(24.6)$ & $25.0 \pm 5.1(24.5)$ & 0.724 \\
\hline Waist circumference $(\mathrm{cm})$ & $87.0 \pm 13.2(85.5)$ & $86.1 \pm 13.3(88.4)$ & $86.7 \pm 12.8(84.8)$ & $87.6 \pm 13.7(86.0)$ & 0.469 \\
\hline Hip circumference $(\mathrm{cm})$ & $94.3 \pm 11.7(94.0)$ & $94.1 \pm 12.3(94.8)$ & $94.5 \pm 11.7(93.8)$ & $94.2 \pm 11.4(93.8)$ & 0.853 \\
\hline Body fat $(\%)$ & $28.3 \pm 8.8(28.3)$ & $28.0 \pm 8.6(26.6)$ & $28.2 \pm 8.6(28.0)$ & $28.5 \pm 9.1(29.7)$ & 0.651 \\
\hline \multicolumn{6}{|l|}{ Plasma lipid profile } \\
\hline Triglyceride (mg/dL) & $134.7 \pm 68.6(109.0)$ & $133.2 \pm 72.2(110.5)$ & $140.9 \pm 77.4(112.5)$ & $127.4 \pm 53.3(107.0)$ & 0.081 \\
\hline HDL cholesterol (mg/dL) & $50.7 \pm 44.4(43.0)$ & $54.5 \pm 59.8(42.5)$ & $52.1 \pm 51.3(43.0)$ & $48.0 \pm 23.1(44.0)$ & 0.322 \\
\hline Plasma leptin $(\mathrm{ng} / \mathrm{mL})$ & $7.4 \pm 8.8(4.0)$ & $7.1 \pm 9.4(3.5)$ & $7.4 \pm 9.2(4.0)$ & $7.5 \pm 8.1(5.0)$ & 0.871 \\
\hline \multicolumn{6}{|l|}{ Dietary intake } \\
\hline Total energy (kcal) & $2043.5 \pm 775.6(1884.5)$ & $2060.1 \pm 773.9(1914.4)$ & $2005.8 \pm 761.1(1833.9)$ & $2086.2 \pm 797.6(2000.3)$ & 0.409 \\
\hline Protein $(\mathrm{g})$ & $60.0 \pm 29.3(55.7)$ & $60.6 \pm 25.2(56.8)$ & $57.8 \pm 27.3(54.1)$ & $62.5 \pm 33.1(59.5)$ & 0.195 \\
\hline Fat $(\mathrm{g})$ & $53.5 \pm 29.7(47.8)$ & $52.0 \pm 25.6(43.8)$ & $52.6 \pm 31.4(47.4)$ & $55.2 \pm 28.9(48.6)$ & 0.384 \\
\hline Carbohydrate $(\mathrm{g})$ & $331.8 \pm 131.8(307.4)$ & $338.0 \pm 128.6(312.9)$ & $325.5 \pm 129.2(294.1)$ & $337.7 \pm 136.7(313.2)$ & 0.502 \\
\hline Physical activity (METS-minute) & $5517.2 \pm 5666.4(3689.0)$ & $5269.6 \pm 6495.8(3396.7)$ & $5825.3 \pm 5682.6(4133.8)$ & $5210.0 \pm 5316.5(3554.5)$ & 0.417 \\
\hline
\end{tabular}

BMI: body mass index; HDL: high density lipoprotein; METS: metabolic equivalent of task * Data is shown as mean \pm standard deviation (median) ${ }^{*}$ Independent $t$-test analysis. 
Table 2. Correlation between leptin and adiposity within UCP2 genotypes.

\begin{tabular}{ccccc}
\hline & \multicolumn{2}{c}{ AA + GA $(\boldsymbol{n}=\mathbf{2 3 8})$} & \multicolumn{2}{c}{ GG $(\boldsymbol{n}=\mathbf{1 4 2})$} \\
\hline Age & $\boldsymbol{r}$ & $\boldsymbol{p}$ & $\boldsymbol{r}$ & $\boldsymbol{p}$ \\
Body weight & -0.021 & 0.742 & 0.071 & 0.400 \\
Height & 0.415 & $<0.0001$ & 0.321 & $<0.0001$ \\
Body mass index & -0.302 & $<0.0001$ & -0.365 & $<0.0001$ \\
Waist circumference & 0.640 & $<0.0001$ & 0.567 & $<0.0001$ \\
Hip circumference & 0.629 & $<0.0001$ & 0.497 & $<0.0001$ \\
Body fat (\%) & 0.709 & $<0.0001$ & 0.503 & $<0.0001$ \\
Triglyceride & 0.002 & 0.974 & -0.626 & $<0.0001$ \\
HDL cholesterol & 0.150 & 0.022 & 0.019 & 0.303 \\
\hline
\end{tabular}

Table 3. Correlation between leptin and lifestyle factors within UCP2 genotypes.

\begin{tabular}{ccccccc}
\hline & \multicolumn{3}{c}{ AA + GA $(n=238)$} & \multicolumn{3}{c}{ GG $(n=142)$} \\
\hline Energy intake & $\boldsymbol{r}$ & $\boldsymbol{p}^{a}$ & $\boldsymbol{p}^{c}$ & $\boldsymbol{r}$ & $\boldsymbol{p}^{a}$ & $p^{c}$ \\
Protein intake & -0.324 & $<0.0001$ & 0.004 & -0.111 & 0.188 & 0.148 \\
Fat intake & -0.268 & $<0.0001$ & 0.001 & -0.065 & 0.439 & 0.104 \\
Carbohydrate & -0.186 & 0.004 & 0.003 & 0.064 & 0.450 & 0.779 \\
Total physical activity & -0.323 & $<0.0001$ & 0.031 & -0.158 & 0.060 & 0.140 \\
\hline
\end{tabular}

$p^{\mathrm{a}}=p$-value for Pearson correlation analysis $p^{\mathrm{c}}=p$-value for partial correlation analysis controlled for age, gender and body weight.

\section{Discussions}

This study was aimed to elucidate the role of UCP2 gene polymorphism on leptin resistance by taking account subjects dietary intake as a response to leptin production. Leptin is a protein known by its ability to suppress dietary intake by reducing appetite [5]. In this study, we showed the interaction between UCP2 gene polymorphism with dietary intake by the modulation response to leptin. First, leptin was significantly lower in overweight subjects with AA + GA genotypes than those with GG genotype. Second, in subjects with AA+GA genotypes leptin concentration was inversely correlated dietary intake while this correlation was not seen in GG genotype.

UCP2 is a protein that involved in energy metabolism and the polymorphism of this gene was associated with obesity $[11,12,16]$. It was previously reported that mRNA expression of UCP2 at the intraperitoneal adipose tissue of obese individuals is lower than their normal counterparts [17]. Interestingly, the study also reported that the -866 genotype of UCP2 gene was associated with intraperitoneal adipose tissue UCP2 mRNA expression [17]. The A allele of -866G/A UCP2 gene polymorphism was associated with higher UCP2 mRNA expression compared to those with the $G$ allele. It was suggested that $-866 \mathrm{G} / \mathrm{A}$ polymorphism in the UCP2 gene promoter influence exon- 8 insertion:deletion transcript ratio and trans-activating effect in human adipocyte cell line [17].

In order to test the association between UCP2 gene polymorphism and obesity, subjects were divided into 2 groups: AA + GA and GG genotype. This is based on previous finding which showed that the effect of AA and GA on obesity are similar while GG has a strong effect [17]. In this study, we showed that there were no difference on adiposity, leptin, lipid profile and lifestyle between AA + GA and GG genotypes.

There was no association between UCP2 gene polymorphism on leptin concentration in all subjects. This result is similar to those found in Italian [18] and Indian [19] population. Because leptin production is directly correlated with adiposity [4], the association between UCP2 and leptin according to subject's adiposity statuses (normal weight, overweight and obese). Leptin was significantly higher in overweight subjects with GG genotype than those with AA + GA genotypes and this association was not seen in normal weight subjects. This result indicated that subjects in the GG group had less 
leptin sensitivity compared to those in AA + GA group. It was previously suggested that leptin has the ability to reduce body weight by increasing energy expenditure and lowering appetite, especially when adiposity was increased [20,21]. The lack of leptin efficiency on inducing normal body weight in those who are overweight or obese has been proposed as leptin resistance [22]. We suggest that this phenomena was we showed in overweight subjects with GG genotypes of UCP2 gene.

Our finding support previous investigation showed that leptin resistance was genetically inherited [23]. Although it has been reported that UCP2 gene polymorphism was associated with leptin concentration [13], the correlation between UCP2 gene polymorphism and leptin sensitivity is still less understood. However, several reports have supported the theory that leptin requires UCP2 to increase metabolism in mitochondria. In vitro, leptin induced up regulation of UCP2 which in turn increased mitochondrial biogenesis and uncoupled respiration [24]. The impact of leptin on uncoupled respiration has also been reported animal trial and this affect adaptive thermogenesis [25]. In addition, genetic polymorphism in uncoupling proteins (UCP2/3) was associated with improvement of mitochondrial function in human [26].

In subjects with AA + GA genotypes there was a negative correlation between leptin concentration and dietary intake while this correlation was not seen in GG genotype. This is confirmed by the correlation with energy providing nutrients such as fat, carbohydrate, and protein intake. Leptin is a protein which produced as a response to increased adiposity and had the ability to reduce appetite and dietary intake. Therefore, we assumed that the negative correlation between leptin and dietary intake showing a normal dietary response to leptin regulation. This response was not seen in subjects with GG genotype, confirming that their leptin sensitivity was affected. The interaction between UCP2 gene polymorphism, dietary intake and obesity was also seen in our previous studies $[27,28]$.

In this paper, "leptin resistance" or "lower sensitivity" was exhibited by the interaction between circulating plasma leptin and dietary intake. In scientific publications, leptin has been introduced as product of adipose tissue with the ability to control dietary intake and energy metabolism [3]. And the phrase "leptin resistance" has also been mentioned in many papers as one of parameter in animal trial. However, currently there is no standard for definition of "leptin resistance" in human. Leptin resistance was labelled as signature of high leptin concentration in the human body, but this terminology is rather difficult to apply because leptin concentration is increasing as adipose tissue increases [22]. Therefore the definition of leptin resistance should be based on the interaction between circulating leptin concentration and body response to leptin (for example dietary intake and basal energy expenditure). The limitation of measurement is that dietary intake could be controlled not only by appetite, but also by socio-economic, food availability and other factors. Leptin production is affected by several factors, including gender, age, adiposity, physical exercise, feeding and caloric restriction [29]. Gender, age and adiposity were equally distributed in this study. Physical activity was controlled by excluding those who had problems with walking and conducting normal physical activity. Feeding and caloric restriction was controlled by excluding those is currently following certain weight loss or disease specific diet.

\section{Conclusions}

In summary, we showed that genetic variation in $-866 \mathrm{G} / \mathrm{A}$ UCP2 on individual response to leptin. AA + GA genotype had a better leptin sensitivity shown by its response in dietary intake and BMI. These results also shows the possible explanation on how A allele possess a protective effect to obesity. Further study is needed to study the mechanism on how UCP2 gene polymorphism affects leptin signalling and response in human. Analysis on the correlation between leptin and appetite or basal energy expenditure will be interesting to be done in the future.

Acknowledgments: This study was funded by International Research Collaboration (IRec) Grant (IREC Grant No.: 1002/PPSK/910408) (Universiti Sains Malaysia), Community Fund-Faculty of Medicine (Universitas Gadjah Mada) and Young Investigator Awards (Universitas Gadjah Mada). 
Author Contributions: H.F.L., D.C.S., E.H., Y.Y.L. and W.A.M.W.M. conceived and designed the study; H.F.L., D.C.S. and E.H. performed the data collection and processing; H.F.L., D.C.S. and E.H. analyzed the data; Y.Y.L. and W.A.M.W.M. contributed reagents, materials and analysis tools; H.F.L. wrote the paper.

Conflicts of Interest: We stated that there are no conflict of interest regarding editoral and financial issues in this study.

\section{References}

1. Popkin, B.M.; Adair, L.S.; Ng, S.W. Global nutrition transition and the pandemic of obesity in developing countries. Nutr. Rev. 2012, 70, 3-21. [CrossRef] [PubMed]

2. Poirier, P.; Giles, T.D.; Bray, G.A.; Hong, Y.; Stern, J.S.; Pi-Sunyer, F.X.; Eckel, R.H. Obesity and Cardiovascular Disease: Pathophysiology, Evaluation, and Effect of Weight Loss: An Update of the 1997 American Heart Association Scientific Statement on Obesity and Heart Disease From the Obesity Committee of the Council on Nutrition, Physical Activity, and Metabolism. Circulation 2006, 113, 898-918. [CrossRef] [PubMed]

3. Schwartz, M.W.; Woods, S.C.; Porte, D., Jr.; Seeley, R.J.; Baskin, D.G. Central nervous system control of food intake. Nature 2000, 404, 661-671. [CrossRef] [PubMed]

4. Klein, S.; Coppack, S.W.; Mohamed-Ali, V.; Landt, M. Adipose Tissue Leptin Production and Plasma Leptin Kinetics in Humans. Diabetes 1996, 45, 984-987. [CrossRef] [PubMed]

5. Zhou, Y.; Rui, L. Leptin signaling and leptin resistance. Front. Med. 2013, 7, 207-222. [CrossRef] [PubMed]

6. Fan, S.H.; Say, Y.H. Leptin and leptin receptor gene polymorphisms and their association with plasma leptin levels and obesity in a multi-ethnic Malaysian suburban population. J. Physiol. Anthropol. 2014, 33, 15. [CrossRef] [PubMed]

7. Chavarria-Avila, E.; Mercado, M.V.D.; Gomez-Bañuelos, E.; Ruiz-Quezada, S.L.; Castro-Albarran, J.; Sánchez-López, L.; Martín-Marquez, B.T.; Navarro-Hernández, R.E. The Impact of LEP G-2548A and LEPR Gln223Arg Polymorphisms on Adiposity, Leptin, and Leptin-Receptor Serum Levels in a Mexican Mestizo Population. BioMed Res. Int. 2015, 2015, 539408. [CrossRef] [PubMed]

8. Sahin, D.S.; Tumer, C.; Demir, C.; Celik, M.M.; Celik, M.; Ucar, E.; Gunesacar, R. Association with Leptin Gene c.-2548 G>A Polymorphism, Serum Leptin Levels, and Body Mass Index in Turkish Obese Patients. Cell Biochem. Biophys. 2013, 65, 243-247. [CrossRef] [PubMed]

9. Azzu, V.; Brand, M.D. The on-off switches of the mitochondrial uncoupling proteins. Trends Biochem. Sci. 2010, 35, 298-307. [CrossRef] [PubMed]

10. Ricquier, D. Respiration uncoupling and metabolism in the control of energy expenditure. Proc. Nutr. Soc. 2005, 64, 47-52. [CrossRef] [PubMed]

11. Salopuro, T.; Pulkkinen, L.; Lindström, J.; Kolehmainen, M.; Tolppanen, A.M.; Eriksson, J.G.; Valle, T.T.; Aunola, S.; Ilanne-Parikka, P.; Keinänen-Kiukaanniemi, S.; et al. Variation in the UCP2 and UCP3 genes associates with abdominal obesity and serum lipids: The Finnish Diabetes Prevention Study. BMC Med. Genet. 2009, 10, 94. [CrossRef] [PubMed]

12. Jun, H.S.; Kim, I.K.; Lee, H.J.; Lee, H.J.; Kang, J.H.; Kim, J.R.; Shin, H.D.; Song, J. Effects of UCP2 and UCP3 variants on the manifestation of overweight in Korean children. Obesity 2009, 17, 355-362. [CrossRef] [PubMed]

13. Rance, K.A.; Johnstone, A.M.; Murison, A.M.; Duncan, J.S.; Wood, S.G.; Speakman, J.R. Plasma leptin levels are related to body composition, sex, insulin levels and the A55V polymorphism of the UCP2 gene. Int. J. Obes. 2007, 31, 1311-1318. [CrossRef] [PubMed]

14. Scarpace, P.J.; Matheny, M.; Moore, R.L.; Kuma, M.V. Modulation of uncoupling protein 2 and uncoupling protein 3: Regulation by denervation, leptin and retinoic acid treatment. J. Endocrinol. 2000, 164, 331-337. [CrossRef] [PubMed]

15. Ho, P.W.; Liu, H.F.; Ho, J.W.; Zhang, W.Y.; Chu, A.C.; Kwok, K.H.; Ge, X.; Chan, K.H.; Ramsden, D.B.; Ho, S.L. Mitochondrial uncoupling protein-2 (UCP2) mediates leptin protection against MPP+ toxicity in neuronal cells. Neurotox. Res. 2010, 17, 332-343. [CrossRef] [PubMed]

16. Zhang, M.; Wang, M.; Zhao, Z.T. Uncoupling protein 2 gene polymorphisms in association with overweight and obesity susceptibility: A meta-analysis. Meta Gene 2014, 2, 143-159. [CrossRef] [PubMed] 
17. Esterbauer, H.; Schneitler, C.; Oberkofler, H.; Ebenbichler, C.; Paulweber, B.; Sandhofer, F.; Ladurner, G.; Hell, E.; Strosberg, A.D.; Patsch, J.R.; et al. A common polymorphism in the promoter of UCP2 is associated with decreased risk of obesity in middle-aged humans. Nat. Genet. 2001, 28, 178-183. [CrossRef] [PubMed]

18. Maestrini, S.; Podestà, F.; Di Blasio, A.M.; Savia, G.; Brunani, A.; Tagliaferri, A.; Mencarelli, M.; Chiodini, I.; Liuzzi, A. Lack of association between UCP2 gene polymorphisms and obesity phenotype in Italian Caucasians. J. Endocrinol. Invest. 2003, 26, 985-990. [CrossRef] [PubMed]

19. Srivastava, N.; Prakash, J.; Lakhan, R.; Agarwal, C.G.; Pant, D.C.; Mittal, B. A common polymorphism in the promoter of UCP2 is associated with obesity and hyperinsulenemia in northern Indians. Mol. Cell. Biochem. 2010, 337, 293-298. [CrossRef] [PubMed]

20. Friedman, J.M. Leptin and the regulation of body weigh. Keio J. Med. 2011, 60, 1-9. [CrossRef] [PubMed]

21. Pandit, R.; Beerens, S.; Adan, R.A.H. Role of leptin in energy expenditure: The hypothalamic perspective. Am. J. Physiol. Regul. Integr. Comp. Physiol. 2017, 312, R938-R947. [CrossRef] [PubMed]

22. Myers, M.G., Jr.; Heymsfield, S.B.; Haft, C.; Kahn, B.B.; Laughlin, M.; Leibel, R.L.; Tschöp, M.H.; Yanovski, J.A. Challenges and opportunities of defining clinical leptin resistance. Cell Metab. 2012, 15, 150-156. [CrossRef] [PubMed]

23. Lee, J.H.; Reed, D.R.; Price, R.A. Leptin resistance is associated with extreme obesity and aggregates in families. Int. J. Obes. 2001, 25, 1471-1473. [CrossRef] [PubMed]

24. Calgani, A.; Delle Monache, S.; Cesare, P.; Vicentini, C.; Bologna, M.; Angelucci, A. Leptin contributes to long-term stabilization of HIF- $1 \alpha$ in cancer cells subjected to oxygen limiting conditions. Cancer Lett. 2016, 376, 1-9. [CrossRef] [PubMed]

25. Henry, B.A.; Andrews, Z.B.; Rao, A.; Clarke, I.J. Central leptin activates mitochondrial function and increases heat production in skeletal muscle. Endocrinology 2011, 152, 2609-2618. [CrossRef] [PubMed]

26. Kim, S.; Myers, L.; Ravussin, E.; Cherry, K.E.; Jazwinski, S.M. Single nucleotide polymorphisms linked to mitochondrial uncoupling protein genes UCP2 and UCP3 affect mitochondrial metabolism and healthy aging in female nonagenarians. Biogerontology 2016, 17, 725-736. [CrossRef] [PubMed]

27. Luglio, H.F.; Eurike, D.; Huriyati, E.; Julia, M.; Susilowati, R. Gene-lifestyle interaction: The role of SNPs in UCP2 $-866 \mathrm{G} / \mathrm{A}$ and UCP3 $-55 \mathrm{C} / \mathrm{T}$ on dietary intake and physical ctivity in Indonesian obese female adolescents. Med. J. Nutr. Metab. 2016, 9, 87-93. [CrossRef]

28. Huriyati, E.; Luglio, H.F.; Ratrikaningtyas, P.D.; Tsani, A.F.A.; Sadewa, A.H.; Juffrie, M. Dyslipidemia, Insulin Resistance and Dietary Fat Intake in Obese and Normal Weight Adolescents: The Role of Uncoupling Protein 2 Gene Polymomrphism. Int. J. Mol. Epidemiol. Genet. 2016, 7, 67-73. [PubMed]

29. Dagogo-Jack, S. Physiological and Hormonal Factors that Influence Leptin Production. In Leptin, 1st ed.; Dagogo-Jack, S., Ed.; Springer: Basel, Switzerland, 2015; pp. 45-65. 